\title{
The Effects of Sexuality Education in the Control of HIV among Adolescent Students in Benin City.
}

\author{
Nwizugbe Obiageri Ezenwa, PhD. \\ Is the Senior Monitoring and Evaluation Advisor, JSI Research \& Training/TSHIP, USAID project.
}

\begin{abstract}
Given the significant number of young people in developing countries seriously affected by sexually transmitted diseases like HIV, it is crucial that work be undertaken to ensure their protection. This involves providing the adolescents with information and resources and creating a climate of understanding to young people about their reproductive and sexual needs.

In order to investigate the effects of sexuality education in the control of HIV among the adolescents' students in Benin City, a cross-sectional urban based study was conducted among 500 randomly selected adolescent students in two randomly selected secondary schools.

Findings revealed that $22 \%$ of the adolescents were sexually active with multiple sexual partners in some cases. Over 50\% of respondents do not discuss issues of sexuality with their parents; instead get information from peers, electronic and print media. 50\% are not fully aware of HIV preventive measures. It was equally found that adolescents were well informed about their sexuality and HIV through the mass media and peer groups. An overwhelming majority of the adolescents stayed away from sex (82\%) and their reasons were because they were informed that they could contract disease from sex (33.6\%) and another 31.9\% said it is a sin. Unfortunately, among the adolescents who are sexually active (18\%) and who claimed to be well informed about how to contract or prevent HIV (100\%), also stated that they have multiple sex partners (100\%), have sex with commercial sex workers (44\%), and engage in sexual intercourse without condoms (78\%).
\end{abstract}

\subsection{What is Adolescence?}

\section{Introduction:}

The beginning of adolescence has both a socio-cultural and biological components; both characterized by a profound lack of specificity. The biological component manifests itself beginning from the age of puberty, that is, between 11 to 15 years (Tanner, 2007) ${ }^{1}$. The outward manifestation of this stage includes the enlargement of the testis, the enlargement of breasts and a change in the voice crescendo.

The socio-cultural aspect represents a set of new roles associated with the age-grade of the child. According to Kinsey $(2008)^{2}$ as this child gradually becomes conscious of these societal expectations and begins to accept them through imitation of his/her peers, the child begins to manifest overt signs of super ego formation, which becomes the primary source of behavior control and greater involvement in peer groups influences. Later the adolescences also manifest some exuberance such as the right to leave school at will and to consent to coitus. It is a time when dating system becomes the central aspect of life style and masturbation begins to occur at fairly high level of frequency.

According to Borowitz, $(2003)^{3}$ malesparticularly get committed to masturbation as the major source of sexual outlet. For females, on the other hand, the most direct expression of puberty is the commencement of menstrual period.

\subsection{What is sexuality and sexual education?}

To understand sexuality, one would need to know the different components of sexuality. It is a combination of anatomic sex, gender identity and sexual orientation. Anatomic Sex refers to the sex organs that one is born with, that is, either a boy (with a penis and testicles) or a girl (with uterus, vagina and ovaries). Gender identity relates to how you feel inside, and whether you "feel" like a boy or a girl, that is, masculine or feminine. When someone feels like the opposite sex, it is referred to as transgender. Sexual orientation refers to the state of having stronger physical and emotional attractions to others, either with people of opposite sex (heterosexual), people of the same sex (homosexual or lesbianism) or both (bisexual). Sexual orientation is influenced by many factors, including, anatomic sex, gender identity, the society you live in (environment). The act of studying and understanding sexuality either through formal learning of from informal sources is referred to as sexuality education.

According to Wikipedia $\{2006)^{4}$ Sex education is instruction on issues relating to human sexuality, including human sexual anatomy, sexual reproduction, sexual intercourse, reproductive health, emotional relations, 
reproductive rights and responsibilities, abstinence, birth control, and other aspects of human sexual behavior. Common avenues for sex education are parents or caregivers, formal school programs, and public health campaigns.( http://en.wikipedia.org/wiki/Sex_education)

\subsection{What is STI/HIV?}

Sexual activity involves the expression of intimacy such as by spending time with another person, holding hands, and kissing. This attraction may sometimes go beyond this and may invite closer intimacy like going to bed. Sexual intercourse refers to sex involving a man's penis being placed into a woman's vagina. When a man ejaculates during sexual intercourse, this semen is released into the woman's vagina. The act of inserting the penis into the vagina and releasing semen during intercourse is what promotes sexually transmitted disease. According to Tracee Cornforth (2006) ${ }^{5}$, in her book "About Common Health's Disease and Condition "STDs are caused by bacteria and viruses. STDs caused by bacteria include chlamydia, gonorrhea, trichomoniasis and syphilis. These STDs can be treated and cured with antibiotics. STDs caused by viruses include HIV/AIDS, genital herpes, genital warts, and cytomegalovirus. Sexually transmitted infections (STI) are often associated with ejaculation which is the main reason for engaging in sexual activity. These STDs can be controlled, but not cured. There is no way to get any of these viruses out of a person's body once he or she has become infected. Finding and treating STDs early is the best way to take care of you.

HIV means Human Immunodeficiency Syndrome. This is a virus that can survive only in the blood cells of human beings. For now it has no officially celebrated cure. Though there are Ante-Retroviral Therapy drugs which are capable of reducing its effects but a cure is yet to be found.

It is a form of sexually transmitted infection (STI). Below are ways that a person can contract HIV.

1. Sexual intercourse with an infected person..

2. The transfusion of an infected person.

3. Sharing of sharp items or razor with an infected person

4. Sharing barbing clipper with an infected person.

5. From an infected mother to an unborn baby.

6. From an infected mother to her baby during birth.

7. From an infected mother to her baby during breast feeding.

\subsection{How to avoid getting HIV.}

According to HIV Insite ${ }^{6}$ (See http://hivinsite.ucsf.edu/hiv? page=basics-00-05) A Comprehensive, upto-date information on HIV/AIDS treatment, prevention, and policy from the University of California San Francisco, HIV is a virus that infects people by getting inside their blood cells. To avoid getting HIV, you must prevent the blood, semen, vaginal fluids, or breast milk of someone who is infected from entering your body through your mouth, vagina, anus, tip of your penis, or breaks in your skin.

\subsection{Statement of the Problem}

In some developing countries, up to $60 \%$ of all new HIV infections occur among 15-24 years old. Gender, Socio-economic status, sexuality and age are important factors structuring HIV vulnerability. Unequal power relations between women and men, for example, may render young women, especially vulnerable to coerced or unwanted sex, and can also influence the capacity of young women to influence when, where and how sexual relations occur (Rivers \&Angleton, 1998) ${ }^{7}$.

The consequences of HIV/AIDS can be far-reaching for young people. Not only does HIV disease have terrible consequences for the individual, causing serious illness and eventual death, it has the potential to trigger negative social reactions. Across the world, people with HIV/AIDS routinely experience discrimination, stigmatization and ostracization (Auer, 1996; Malcolm et al 1998) ${ }^{8}$. Children and young people who are orphaned by the epidemic, and who themselves may be infected, are sometimes left without the support of adults (Levine, Michaels \& Back, 1996). For women and adolescent girls, the consequence of AIDS can be particularly dire. There is strong evidence, for example, that in some countries women may be "blamed" for HIV disease even in circumstances where they have been infected by remaining faithful to their husband or other male partner (Bharat \&Angleton, 1990) ${ }^{9}$.

Despite the reported consequences of HIV the knowledge level of the young population seems to even compound the situation. As will be reported later in this study, young population seems not to either have the opportunity to get information for HIV prevention or is hindered by socio-cultural factors to shy away from using the information available to them. This increases their vulnerability to HIV.

Given the significant number of young people in developing countries seriously affected by sexually transmitted diseases like HIV, it is crucial that work be undertaken to ensure their protection. This involves providing the adolescents with information and resources and creating a climate of understanding to young people about their 
reproductive and sexual needs. It is desire to knowing the relationship between this information inhibition and vulnerability to HIV that forms the crux of this study.

\subsection{Objectives}

The main aims of this research are:

- To examine the Effects of Sexuality Education in the Control of HIV among Adolescent Students in Benin City.

- To make recommendations for the control of HIV among adolescent students.

\subsection{Health Concerns with Adolescents:}

\section{Literature Review}

According to the study conducted by Sharmila et al.(2001) ${ }^{10}$, among 120 male adolescents in an urban slum community in Mumbai, $87.5 \%$ of the respondents had received information about sex and sexuality from their peers and older friends. Nocturnal emission and masturbation were the major health concern for $40 \%$ of those interviewed. $7.5 \%$ were sexually active.

There are increasing pressures on young people to be sexually active and, in the case of boys, to have several different partners (Rivers \& Aggleton, 1998) ${ }^{11}$. Evidence from a variety of countries suggests that the age at which young people become sexually active may be falling (Fee \&Yousef, 1993) ${ }^{12}$. In Uganda, for example, almost 50 percent of young men and nearly 40 per cent of young women recently surveyed reported having had sex by the age of fifteen years (Konde-Lule et al, 1997) ${ }^{13}$. In Dar as Salaam, Tanzania 60 per cent of 14 year-old boys and 35 per cent of girls have reported that they are sexually active (Fuglesang, 1997) ${ }^{14}$. In a recent Brazilian school-based study, 36\% of females reported having had intercourse by the age of 13 (Weiss, Whelan \& Gupta, 1996) ${ }^{15}$.

Young people often have less access to information services and resources than those who are older (Friedman, 1993; Angleton and Rivers) ${ }^{16}$. Health services are rarely designed specifically to meet their needs, and health workers only occasionally receive specialist training in issues pertinent to adolescent sexual health (Friedman, 1993; Zelaya et al, 1997, World Health Organization, 1998) ${ }^{17}$.

\subsection{Information on sexuality}

Some adults believe that young people are of their nature sexually promiscuous and that giving them information about sex will make young people more sexually active (Friedman, 1993). As a result, sex education in schools either does not take place or promotes only certain risk reduction measures. Yet there is now clear evidence that well-designed programs of sex education, which include messages about safer sex as well as well as those about abstinence, may delay the onset of sexual activity, and reduce the number of sexual partners, and increase contraceptive use among those who are already sexually active (Grunseit et al, 1997; Grunseit 1997) ${ }^{18}$.

In countries as different as India and Nicaragua, parents and children report that they do not talk to each other about sex (George \& Jaswal, 1995; Zelaya et al, 1997) ${ }^{19}$.

\subsection{Adolescent lifestyle, sexuality exposure and vulnerability to HIV.}

That said, there are a number of structural as well as individual factors which may heighten young people's vulnerability to HIV and AIDS. While developing countries in Asia, Africa and Southern and Central America vary in terms of culture, religion and socio-economic factors, young people living in them share a number of experiences, which render them particularly vulnerable to HIV infection. Young people in poverty or facing the threat of poverty may be particularly vulnerable to sexual exploitation through the need to trade or sell sex in order to survive (World Health Organization, 1998).Many are at heightened risk of acquiring STIs including HIV. More than half of 141 street children recently interviewed in South Africa, for example, reported having exchanged sex for money, goods or protection, and several indicated that they had been raped (Swart-Kruger \& Richter, 1997) ${ }^{20}$.

Street children in Jakarta, Indonesia, have reported that being forced to have sex is one of the greatest problems that they faced living on the streets (Black and Farrington, 1997) ${ }^{21}$. In Brazil, where it is estimated that 7 million young people live in the streets, between 1.5 to $7.5 \%$ of those tested for HIV are infected (Filgueiras, 1993). In addition to risk from unprotected sex activity, rape and coercion, the high prevalence of injecting drug use on the streets in Brazil and some other countries may heighten young people's vulnerability to HIV (Filgueiras, 1993) ${ }^{22}$

Sometimes, the exchange of sex for goods and money may be regularized in the form of what have been called "Sugar daddy" and "sugar mummy" relationships. In Tanzanian, for example, young girls frequently report having older men as sexual partners (Fuglesang, 1997) ${ }^{23}$. In Kenya, young girls report that they are courted by older men seeking sex, and may find themselves in situations in which it is difficult to 
negotiate a way out (Balmer et al, 1997) ${ }^{24}$.Young women in many parts of the developing world have little control over how, when and where sex takes place (Gupta, Weiss \& Mane, 1996) ${ }^{25}$. In Benin City, Nigeria the young girls call their older men sex mates as "sugar daddy".

\subsection{Gender imbalance in sexuality education, claim to virginity and vulnerability to STI/HIV.}

In perhaps the majority of counties, there are strong pressures on young unmarried women to retain their virginity (Weiss, Whelan \& Gupta, 1996; Petchesky \& Judd, 1998) ${ }^{26}$. However, the social pressure to remain a virgin can contribute in a number of ways to the risk of STIs and HIV which young women face. In some contexts, young women may engage in risky sexual practices, such as anal sex, as means of protecting their virginity (Gupta, Weiss and Mane, 1996) ${ }^{27}$.

Sexually active young women are also discouraged from discussing sex too openly with their own partners; since women are encouraged to be ignorant and inexperienced. This means that young women are unlikely to be able to communicate their need of safer sex with partners. In Kenya, for example, a recent study revealed that young women felt that they did not have control over their sexuality - instead girls learned that sex was something that happened to them. It was not something they could initiate or actively participate in (Balmer et al, 1997) ${ }^{27}$.

In addition to the emphasis widely placed on remaining 'chaste', girls are commonly socialized to be submissive to men (Zelaya et al, 1997) ${ }^{28}$. Girls are often pressured by boys to have sex as a proof of love and obedience. Not surprisingly under conflicting pressures, girls have little influence over decision-making or the use of contraception (Zelaya et al, 1997) ${ }^{29}$. In a recent review of research conducted in seven countries, including Nigeria, Egypt, Mexico and the Philippines, Petchesky and Judd $(1998)^{30}$ concluded that even where sexually active young women are aware of HIV/AIDS and measures to protect against infection, rarely do they have the power to ensure that condoms are used.

In some cultures, boys are actively encouraged by both their peers and family members to use their adolescent year to experiment sexually (Weiss, Whelan \& Gupta, 1996) ${ }^{31}$.In Nicaragua, for example, where virginity is highly valued among young women, having multiple sexual partners is taken as a sign of virility in young men (Zelaye et al, 1997) ${ }^{32}$. Here, teenage boys face social pressures form older men (including fathers, older brothers and uncle) to have sex, as early as possible and, in the recent past, it was not uncommon for fathers to arrange for their son's sexual initiation with a sex worker (Zalaya et al, 1997) ${ }^{33}$. So while for girls, public disclosure of sexual activity leads to dishonor, bragging about sex is common for boys. According to Berglund et al. 1997 note that for Nicaraguan men the pressure to be sexually active and multi-partnered may be so great that those do not fulfill this expectation are open to ridicule by their peers for not being a real men.

In South Africa, for example, having many sexual partners is reported as being equated with popularity and importance among young men (Abdul-Karim and Morar, 1995) ${ }^{34}$. Interviews with high school students in Zimbabwe indicate that while boys can have (and indeed should have) many girlfriends, girls should stick to one (Bassett \& Mhloyi, 1991). Although not all young men conform to the dominant versions of masculinity described above, those who fail to do so are often ridiculed and subjected to peer pressures to conform.

However, research in a variety of contexts shows that because sexual ignorance is not acceptable young men are reluctant to admit that they are lacking in knowledge (Weiss, Whelan \& Gupta, 1996) ${ }^{35}$. So while young women risk their sexual health because they must appear to be ignorant and so cannot openly seek information, young men risk their sexual health because they must appear to be knowledgeable and so cannot openly seek information either.

\subsection{FGM and HIV Vulnerability}

Beyond these behaviours, which carry clear HIV related risks, are issues concerning local cultures and traditions such as female genital mutilation (FGM) and male circumcision, both of which are perpetuated upon young people by those who are older. When practiced as part of group initiation ceremonies or in ways involving the sharing of razors, knives and other cutting instruments, the risk of HIV infection being transmitted from one person to another can be considerable high (Petchesky\& Judd, 1998) ${ }^{37}$. This risk is even increased by the singular fact that the sharp objects used during the initiation ceremonies are never subjected to any standard sterilization process.

The world Health Organization and other bodies have condemned the practice of FGM on both medical and human rights grounds and, in 1993, passed a resolution at the $46^{\text {th }}$ World Health Assembly calling for member states to act to eliminate harmful traditional practices (World Health Organization, 1993) ${ }^{38}$.

\subsection{Sex Education within the Family and Vulnerability to STI/HIV.}

The effectiveness of traditional family expectations and structures in shaping sexual beliefs, expectation and behaviours appears to have been substantially weakened by population movement, with little 
continuity in sex education within the family, young people report that their peers are more relied upon for information and guidance about sex (Runganga \&Angleton, 1998) ${ }^{39}$. There is evidence from elsewhere in Africa to suggest that peers have become a more important source of knowledge, advice and support. In Malawi, for example, sixty percent of girls recently interviewed reported having learned about menstruation from friends, not from their grandmother or from their advisors as traditionally occurred (Helitzer-Allen, 1997) ${ }^{40}$. The media is relied upon more than was the case in the past to provide information and guidance about sex and sexual relationships.

Parents and family members are reluctant to discuss sexual matters with young people. Women interviewed in a variety of contexts report that they were told very little about sex and reproduction prior to marriage (Bang et al, 1989) ${ }^{41}$. In rural and urban areas, young people, especially girls, remain uniformed since sex and reproduction are considered distasteful and embarrassing subjects (Jejeebhoy, 1998) ${ }^{42}$. In a recent study conducted in Mumbai, one mother interviewed said that adult do not want to frighten young girls by talking about sex (George \&Jaswal, 1995) ${ }^{44}$. The peer group therefore constitutes an important source of information, as does the developing mass media (Jejeebhoy, 1998) ${ }^{45}$.

\subsection{Work with Young People In and Out of Schools.}

In contexts where large numbers of young people attend school, school-based programs can offer an appropriate setting for HIV-related education. In Tanzania, for example, a school-based program called Ngao (shield) was designed to reduce risks of HIV infection and reduce discrimination attitudes towards people living with AIDS. The program consisted of factual information, posters, songs, poetry and performances of younger pupils generated by the students. Panel discussions were also held with elders and parents. Six months after the program, pupils who had been exposed to Ngao reported significant increases in AIDS-related knowledge and more positive attitudes to people living with AIDS in comparison to those who had not (Klepp et al, 1994) ${ }^{46}$.

Importantly, in reviewing a number of programs of sex education for young people, Grunseit (1997) ${ }^{47}$ has noted that sex education programs have greatest impact if undertaken prior to the onset of sexual activity.

In Nigeria, young University graduates are given one month orientation on sexuality education, especially with regards to HIV prevention, care and supported of the infected and affected persons. This is done while they are still in their orientation camp in preparation for their compulsory one year post-graduation service to their father-land. Although school-based programs are useful, it is important to note that in many parts of developing world some of the most vulnerable young people do not attend school. Some of these young persons constitute the most at risk group either by their occupation or their chosen life-style. This includes hair dressers, brutel/club ladies, long distant vehicle workers, sedentary workers, military and para-military workers and the gays. According to Weiss, Wheland, Gupta, $(1996)^{48}$, in many parts of the world, including South Asia and Northern Nigeria, young women spend much of time at home and are usually very difficult to meet or reach because of "ba-chiga", meaning don't enter).

\section{Methodology}

A quantitative study design was adopted to conduct this research. A cross-sectional urban-based study was conducted among students in secondary schools in Benin City, using structured questionnaire approach. The questionnaires were self-administered since the target populations are literate enough and the questionnaires were easy to understand. The study was completed within one month.

Two secondary schools were selected by simple random sampling method after obtaining list of all the secondary schools in Benin City, from the Post-primary Education Board. All the students in the schools were then stratified into number of classes and selected by systematic random sampling. An estimated 500 students were selected. This was shared on equal quota per class (given 100 students to JS1, JS2, JS3, SS1 and SS2).

Students with age below 10 years or above 19 years were disqualified since these fallout side the age range for adolescence. Age as at last birthday was used.

\subsection{Data Analysis}

The data were collected and properly coded, edited and collated manually and electronically. Simple percentage was used to tabulate the responses.

\subsection{Limitation Of The Study}

Some students were not willing to give frank information due to sensitive nature of the subject and giving the level of awareness on such issues in our environment.

It is possible that the others may not have been very frank in responding to the questions.

The sample size is rather small when compared with the size of adolescent students. This may have hindered some information concerning sexual activity and sexuality related misconceptions among adolescents. Whatever that were found here may just constitute a "tip of the berg". 


\subsection{Ethical Consideration}

The letter of introduction from my supervisor and the collaborating efforts from the proprietor/school heads encouraged and convinced the students to willingly consent to filling the questionnaire. In order wards, the consent of the students were obtained before the commencement of the questionnaire administration.

\section{Data Presentation}

This is a balanced representation and was deliberate. The ages 10-24 years are referred to as young people, while $15-24$ years is referred to as youth.

This is also a fairly balanced representation and reflects the equal emphasis on gender education in this part of the country unlike in the East where female education and the North where male education is preferred

TABLE -4.1; Respondents by class

\begin{tabular}{|l|l|l|}
\hline & Frequency & $\mathbf{\%}$ \\
\hline JS 1 & 100 & 20 \\
\hline JS 2 & 100 & 20 \\
\hline JS 3 & 100 & 20 \\
\hline SS 1 & 100 & 20 \\
\hline SS 2 & 100 & 20 \\
\hline Total & $\mathbf{5 0 0}$ & $\mathbf{1 0 0}$ \\
\hline
\end{tabular}

Most students write the school certificate examination at SS 2 so that SS 3 is technically non-existent.

TABLE -4.2; Respondents by Socio-economic status of parents

\begin{tabular}{|l|l|l|}
\hline & Frequency & \% \\
\hline Literate/ Professional & 400 & 80 \\
\hline Semi-literate & 100 & 20 \\
\hline Total & $\mathbf{5 0 0}$ & $\mathbf{1 0 0}$ \\
\hline
\end{tabular}

There is a bias here as professions like Business, full time housewife, trading were only combined to qualify as semi-literate since no detailed information could be got.

The students were distributed by their religious denominations. About $90 \%$ of the stated that they are Christians and only $8 \%$ are Muslims. This represents the dominant religion in this part of the country.

TABLE -4.3; Respondents by Ethnic group

\begin{tabular}{|l|l|l|}
\hline & Frequency & \% \\
\hline Bini & 195 & 39 \\
\hline Esan & 60 & 12 \\
\hline Ibo & 90 & 18 \\
\hline Urhobo & 60 & 12 \\
\hline Etsako & 20 & 4 \\
\hline Owan & 20 & 4 \\
\hline Yoruba & 20 & 4 \\
\hline Itsekiri & 20 & 4 \\
\hline Isoko & 5 & 1 \\
\hline Rivers & 5 & 1 \\
\hline Hausa & 5 & 1 \\
\hline Total & $\mathbf{5 0 0}$ & $\mathbf{1 0 0}$ \\
\hline
\end{tabular}

Reflects the dominant tribe in the state

TABLE -4.4; Discussion of Sexuality with parents

Among the students interviewed, more than half (54\%) not discuss the issues of sexuality with parents and only $38 \%$ does while $8 \%$ were undecided.

\section{TABLE -4.5; Preferred Parents}

In terms of openness of parents for sexuality education, more adolescents claimed to discuss issues of sexuality with their mother $(78 \%)$ while $16 \%$ discuss with both parents

Beyond parents as source of sexuality education, the adolescents stated that other sources to include TV as the most popular source of sexuality education (34\%), followed by Magazines (34\%) and their peers (32\%).

TABLE 4.6 Have you had sexual experience?

\begin{tabular}{|l|l|l|}
\hline & Frequency & \% \\
\hline Yes & 90 & 18 \\
\hline
\end{tabular}


The Effects of SexualityEducation in the Control of HIV amongAdolescent Students in Benin City.

\begin{tabular}{|l|l|l|}
\hline No & 410 & 82 \\
\hline Total & $\mathbf{5 0 0}$ & $\mathbf{1 0 0}$ \\
\hline
\end{tabular}

Among the respondents, $18 \%$ of them agreed to have had sexual experience. Denials cannot be ruled out.

TABLE -4.7; Who is your Sexual Partner?

\begin{tabular}{|l|l|l|}
\hline & Frequency & $\mathbf{\%}$ \\
\hline Neighborhood girl/boy/schoolmates & 50 & 56 \\
\hline Commercial sex worker & 40 & 44 \\
\hline Total & $\mathbf{9 0}$ & $\mathbf{1 0 0}$ \\
\hline
\end{tabular}

Expectedly, 56\% of the adolescents agree to have had sexual experience with neighborhood girl/boy/school mate. A shocking $44 \%$ of them agreed to have had sexual experience with commercial sex worker.

TABLE 4.8 Whether used condoms during sexual intercourse.

\begin{tabular}{|l|l|l|}
\hline \multicolumn{1}{|c|}{ Frequency } & $\mathbf{\%}$ \\
\hline No & 70 & 78 \\
\hline Yes & 20 & 22 \\
\hline Total & $\mathbf{9 0}$ & $\mathbf{1 0 0}$ \\
\hline
\end{tabular}

An overwhelming majority (78\%) of the respondents that have had sexual experience stated that they did not use condoms while only $20 \%$ did. This suggests the level of risks to STI and HIV that these children expose themselves to. Is this high level of risk taking due to ignorance or due to share negligence? Further studies will look into this.

TABLE -4.9; Age of first intercourse

\begin{tabular}{|l|l|l|}
\hline & Frequency & \% \\
\hline Below 10yrs & 0 & 0 \\
\hline $10-14$ yrs & 40 & 44 \\
\hline $15-19 y r s$ & 50 & 56 \\
\hline Total & $\mathbf{9 0}$ & $\mathbf{1 0 0}$ \\
\hline
\end{tabular}

Most of the adolescents (56\%) claimed to have experienced sexual intercourse the very first time at the age of $10-14 y r s$, while $44 \%$ admitted having sexual intercourse the very first time at the age of $15-19 y$ rs.

TABLE -4.10; Number of sexual partners

\begin{tabular}{|l|l|l|}
\hline & Frequency & \% \\
\hline 1 & 0 & 0 \\
\hline 2 & 10 & 11 \\
\hline 3 & 80 & 89 \\
\hline Total & $\mathbf{9 0}$ & $\mathbf{1 0 0}$ \\
\hline
\end{tabular}

Surprisingly, no adolescent stated that he/she has only one sexual partner. Majority of them (89\%) admitted having 3 sexual partners and another $11 \%$ said they have 2 partners.

TABLE -4.10B. Why Have You Not Had Sexual Experience?

\begin{tabular}{|l|l|l|}
\hline Responses & Frequency & \% \\
\hline I do not want to contract disease & 400 & 33.6 \\
\hline I am waiting to finish my education & 41 & 3.4 \\
\hline It is a sin & 380 & 31.9 \\
\hline Total & $\mathbf{1 1 9 0}$ & $\mathbf{1 0 0}$ \\
\hline
\end{tabular}

Among those who have never had sexual experience, majority (33.6\%) stated that they abstained from sex because they do not want to contract disease; another $31.9 \%$ stated that they abstained because it is a sin.

TABLE -4.11; Awareness of STD/HIV

\begin{tabular}{|l|l|l|}
\hline & Frequency & \% \\
\hline Yes & 500 & 100 \\
\hline No & 0 & 0 \\
\hline Total & $\mathbf{5 0 0}$ & $\mathbf{1 0 0}$ \\
\hline
\end{tabular}

All the students who were interviewed agreed to have heard the word STI and HIV.

\subsection{How to prevent STD}

All the respondents (100\%) agreed that avoiding sex or using condoms during sex was the best approaches to preventing STD and HIV. 
4.13 Awareness of at least three ways to contracting HIV.

All the respondents were aware of how to contract HIV. Up to $70 \%$ were able to mention at least three ways of contracting HIV and only $30 \%$ mentioned one or two ways. This shows that knowledge of mode of transmission of HIV is quite high among the adolescents.

TABLE 4.14How did you get the information about HIV?

\begin{tabular}{|l|l|l|}
\hline Sources & Frequency & \% \\
\hline Parents/Teachers & 200 & 40 \\
\hline TV/Radio & 120 & 24 \\
\hline Friends & 180 & 36 \\
\hline Total & $\mathbf{5 0 0}$ & $\mathbf{1 0 0}$ \\
\hline
\end{tabular}

Majority (40\%) of the students claimed that they got their HIV information from their school teachers / Parents, $36 \%$ stated friends and the rest $(24 \%)$ stated TV/Radio.

TABLE 4.15Whether there is a relationship between Sexuality Education and the control of HIV.

\begin{tabular}{|l|l|l|}
\hline Responses & Frequency & \% \\
\hline Strong relationship & 440 & 88 \\
\hline No relationship & 40 & 8 \\
\hline Weak relationship & 20 & 4 \\
\hline Total & $\mathbf{5 0 0}$ & $\mathbf{1 0 0}$ \\
\hline
\end{tabular}

An overwhelming majority $(88 \%)$ of the adolescents' respondents stated that there is a strong relationship between Sexuality Education and the control of HIV, $8 \%$ said there is no relationship and $4 \%$ said there is a weak relationship. From this it is very safe therefore to state that there is a relationship between Sexuality Education and the control of HIV.

TABLE 4.16How does sexuality education help to control HIV?

\begin{tabular}{|l|l|l|}
\hline Responses & $\begin{array}{l}\text { Frequency } \\
\text { (multiple responses) }\end{array}$ & \% \\
\hline Teaches us the ways to contract HIV & 480 & 28.6 \\
\hline Teaches us the ways to avoid HIV & 500 & 29.7 \\
\hline Teaches us how to have safe sex by using condom & 100 & 6 \\
\hline Teaches us to avoid sexual intercourse until we marry & 100 & 6 \\
\hline $\begin{array}{l}\text { Teaches us many bad things that sexual intercourse can } \\
\text { cause a stubborn child. }\end{array}$ & 500 & 29.7 \\
\hline Total & $\mathbf{1 6 8 0}$ & $\mathbf{1 0 0}$ \\
\hline
\end{tabular}

Sexuality education Teaches us the ways to avoid HIV (29.7), Teaches us many bad things that sexual intercourse can cause a stubborn child (29.7) and Teaches us the ways to contract HIV (28.6).

\subsection{Summary of findings;}

$54 \%$ of adolescents do not discuss the issues of sexuality with parents and only $38 \%$ does while $8 \%$ were undecided.

More adolescents claimed to discuss issues of sexuality with their mother (78\%) while $16 \%$ discuss with both parents

Other sources of information concerning their sexuality include TV as the most popular source (34\%), Magazines (34\%) and their peers (32\%).

$100 \%$ of students who were interviewed agreed to have heard the word STI and HIV.

100 of the respondents agreed that avoiding sex, or using condoms during sex are the best approaches to preventing STD and HIV.

All the respondents were aware of how to contract HIV. two ways.

Up to $70 \%$ were able to mention at least three ways of contracting HIV and only $30 \%$ mentioned one or

$88 \%$ of the adolescents' respondents stated that there is a strong relationship between Sexuality Education and the control of HIV.

Adolescents suggested that Sexuality education "teaches us the ways to avoid HIV (29.7), Teaches us many bad things that sexual intercourse can cause a stubborn child (29.7) and Teaches us the ways to contract HIV (28.6)".

\section{Discussion of Results}

The study is significant to the academia, the community health workers and the school counselors. Parents should be encouraged to open up opportunities for the adolescents to interact with them and learn, 
especially with respect to their sexuality expectations. The television programs and peers though very important sources of sexuality education, must not replace the role of parents and the formal education.

Though awareness of mode of contracting STI/HIV is quite high among the students, and many do put the information to use. For instance, an overwhelming majority of the adolescents stayed away from sex (82\%) and their reasons were because they were informed that they could contract disease from sex $(33.6 \%)$ and another $31.9 \%$ said it is a sin. However, practice of prevention measures should be strengthened to be more effective in their behavior. This was buttressed by the fact that up to $78 \%$ of the adolescents who are sexually active do not use condoms during sexual act and therefore expose themselves to the risk of contracting STI/HIV. This risk is even heightened by the fact that a shocking $44 \%$ of them had sexual experience with commercial sex workers.

The age of sexual intercourse exposure seems to be declining as $56 \%$ claimed to have experienced sexual intercourse the very first time at the age of 10-14yrs. This requires further investigation. Another source of concern is the fact that $89 \%$ admitted having 3 sexual partners and another $11 \%$ said they have 2 partners.

\section{Recommendations:}

Parents should increase the opportunities for their children to discuss sexuality matters with them. The children should not be allows to groom in the dark. Peer group discussion and television viewing should be made a complementary source of information for the children but definitely not a replacement for parental care and concerns.

An intensive campaign should be mounted by school and government media to enlighten the students on the danger of engaging in early sexual intercourse.

For those that are sexually active, one on one counseling should be given to them, to enable them understand the dangers inherent in engaging in unprotected sex.

The power of sexuality education in the reduction of victims of STI/HIV cannot be over-emphasized. The adolescents themselves admitted that Sexuality education "teaches us the ways to avoid HIV, Teaches us many bad things that sexual intercourse can cause a stubborn child and Teaches us the ways to contract HIV".

\section{Conclusion}

Given the significant number of young people in developing countries seriously affected by sexually transmitted diseases like HIV, it is crucial that work be undertaken to ensure their protection. The beginning of adolescence has both a socio-cultural and biological components which must be understood to be able to address the issues of sexuality as it concerns them.

Sexual activity involves the expression of intimacy such as by spending time with another person, holding hands, and kissing. This attraction may sometimes go beyond this and may invite closer intimacy like going to bed. Sexual intercourse refers to sex involving a man's penis being placed into a woman's vagina. When a man ejaculates during sexual intercourse, this semen is released into the woman's vagina. The act of inserting the penis into the vagina and releasing semen during intercourse is what promotes sexually transmitted disease.

The findings of this present study indicate the urgent needs for more educational interventions. Correct scientific information should be disseminated to adolescents both in formal and informal settings so that they do not pick up sexual myths and misconceptions from their peers. The study also indicated that adolescents actually learn from parents, school, peers and mass media and beyond learning they also put to practice the information they gather. For instance, an overwhelming majority of the adolescents stayed away from sex (82\%) and their reasons were because they were informed that they could contract disease from sex (33.6\%) and another 31.9\% said it is a sin.

This study revealed that only $18 \%$ of the respondents were sexually active. It is possible that the others may not have been very frank in responding to the questions.

This was an urban based study, the sample size is rather small, sexual activity and sexuality related misconceptions among adolescents may be the proverbial "tip of the berg". Majority of respondents shy away from defining components of sexuality.

Sexuality is more than having sex. It is about who you are and how you live. There is need to educate teens on their sexuality. Teens watch TV and browse on pornographic shows and movies that insist that "sex appeal" is a personal quality that people need to develop to the fullest, thus, they are at risk not only from AIDS but from this sort of mass-market encouragement. Teenagers need to understand that satisfying sexual relationships like other relationships require careful thought and wise action.

Clearly parents are in a tough spot. Teens should learn the facts about human reproduction, contraception and sexually transmitted diseases. Health classes and sex education programmes in the school typically present such information. Morals are not abstractions. Parents and other influential adults (at school, 
at church, in the community) need to show teenagers the difference between devotion and infatuation and help them make the distinction in their own hearts.

This study was very revealing and successful one. More studies in this area is therefore recommended.

\section{References}

[1] Angleton P. \& Warwick. I. (2007). 'Young People, Sexuality, HIV and AIDS Education'. In L. Sherr (ed.) AIDS and Adolescents. Amsterdam, Netherlands: Harwood Academic Publishers.

[2] Angleton P. (2006) Global Priorities for HIV/AIDS Intervention Research. International Journal of STD \& AIDS, 7(Suppl.2): 1316.

[3] Angleton P. and Rivers, K. (1998) 'Behavioural interventions for Adolescents' in L. Gibney, R. DiClemente ands. Vermund (eds.) Preventing HIV infection in Developing countries, New York: Plenum Publications.

[4] Ainsworth M. and Over, M. (1994) AIDS and African Development. World Bank Researcher Observer, 9(2): 203-40

[5] Balmer D. H., Gikundi, E., Billengley, M. C., Kihuho, F. G., Kimani, M., Wang'ondu, J., \& Njoroge, H. (1997). Adolescent Knowledge, Values, and Coping Strategies: Implications for health in Sub-Saharan Africa. Journal of Adolescent Health, 21:33-38

[6] Bang R. A., Bang, A. T., Baitule, M., Choudhary, Y., Sarmukaddam, S., \& Tale, O. (1989). High prevalence of gynecological diseases in rural Indian women. Lancet, 1(8629): 8-88.

[7] Bassett M., \&Mholoyi, M. (1991). Women and AIDS in Zimbabwe: The making of an epidemic. International Journal of Health Services, 21(1): 143-56.

[8] Benjamin J.A. (1996). Prevention for Refugees: the case of Rwandans in Tanzania. AIDS Captions, 3(2): 4-9.

[9] Berglund S., Liljestrand, J., Marin, F. D. M., Salgado, N., \&Zelaya, E. (1997). Review background of adolescent pregnancies in Nicaragua: A qualitative approach. Social Science and Medicine, 44(1): 1-12.

[10] Bharat S. and Angleton, P. (1999) Facing the challenge: Household responses to AIDS in India. AIDS Care, 11, $33-49$.

[11] Black B., \& Farrington, A. P. (1997). Preventing HIV/AIDS by promoting life for Indonesian Street children. AIDS Captions, 4(1): 14-17.

[12] Blake S. M., MIddlestadt, S., Lohrmann, D., Lathen, I., Rosdosh, A., Simkin, L., Jimmerson, A., McDonald, G. \& Smith, B. (1995). School-based programs to prevent HIV/AIDS: An Overview of Strategies Used and Lesson Learned. Paper presented at the XLth International Conference on AIDS, Vancouver.

[13] Borowitz G. H. (2003) The capacity to masturbate alone in adolescence. In Annals of adolescent psychiatry, S. C. Feinstein and P. Giovacchini editors, Basic books, New York, Caceres C. and Jimenez, O. (1998). Fletes in Parque Kennedy: Sexual Cultures among Young Men Who Sell Sex to Other Men in Lima. In P. Angleton (ed.) Men who Sell Sex: International Perspectives on Male Prostitution and HIV/ASIDS. London: UCL Press.

[14] Connoly M., Frachet C. N. (1993). Manila Street Children Face Many Sexual Risks. Network, 14(2):4-5.

[15] Dowsett G. \&Aggleton P. (1997). Multi-site Studies of the Contextual Factors Affecting Risk-related Sexual Behaviour Among Young People in Developing Countries, Geneva: UNAIDS.

[16] Elford, J. (1997). 'HIV and AIDS in Adolescence: Epidemiology' in L. Sherr (ed.) AIDS and Adolescence, Amsterdam: Harwood Academic Publishers.

[17] Fee N. \&Yousef M. (1993) Young People, AIDS and STD prevention: Peer Approaches in Developing countries. Unpublished paper prepared for the World health Organization Global Programme in AIDS, Geneva: Switzerland.

[18] Feldman D. A., O’Hara P., Baboo K. S., Chitalu N. W., \& Lu Y. (1997). HIV Prevention Among Zambian Adolescents: Developing a Value Utilization/Norm change Model. Social Science and Medicine, 44(4): 455-468.

[19] Filgueiras A. (1993). Defending Children's Rights: An AIDS prevention Strategy. AIDS Captions, 1(1): 10-13.

[20] Finger W. R. (1993). Seeking Better ways to Teach Youth about AIDS. Network, 14(2): 4-5.

[21] Fuglesang M. (1997). Lessons for life-Past and Present Models, of Sexuality Education in Tanzanian society. Social Science and Medicine, 44(8): 1245-1254.

[22] Grunseit, a., Kippaz, S, Aggleton, P., Boldo, M., \&slutkin, G. (1997). Sexuality Educaation and Young People's Sexual Behaviour: a Review of Studies. Journal of Adolescents Research, 12(4): 421- 453.

[23] Gupta G. R., Weiss, E., \& Mane, P. (1996). 'Talking about sex: a Prerequisite for AIDS prevention'. In L. D. Long \& E. M. Ankrah (eds.) Women's Experiences: an International Perspective Columbia University Press: New York.

[24] Hoffman N. D. \&Futterman, M. D. (1996). 'Youth and HIV/AIDS' in J. Mann \& D. Tarantola (eds.) AIDS in the world II: Global Dimensions, social Roots and Responses. New York: Oxford University Press.

[25] Jejeebhoy S. J. (1998). Adolescent Sexual and Reproduction Behaviour: a Review of Evidence from India. Social Science and Medicine, 40(10): 1257-1290.

[26] Khan S. (1998). Through a window darkly: Men who sell sex to men in India and Bangladesh. In P. Angleton (ed.) Men Who Sell Sex: International Perspective on Male Prostitution and HIV/AIDS > London: UCL Press.

[27] Klepp K. I., Ndeki, s. N., Seha, A. M., Hannan, P., Lyimo, B. A., Msuya, M. H., Irema, M. N., \& Schreiner, A. (1994). AIDS education among primary school children in Tanzania: an evaluation study. AIDS, 8:11157-1162.

[28] Ligouri A. L. and Aggleton P. (1998) Aspects Male sex Work in Mexico City. In P. Aggleton (ed.) Men Who Sell Sex: International perspectives on Male Prostitution and HIV/AIDS. London: UCL Press.

[29] Ratnapala, N. (1998) Male Sex Work in Sri Lanka. In P. Aggleton (ed.) Men Who Sell Sex: International Perspective on Male Prostitution and HIV/AIDS> London: Press.

[30] Ruganga A. O, \& Aggleton P. (1998): Migration, the family and the transformation of a sexual culture. Sexualityes, 1(1): 63-81.

[31] Sharmila S., Paul Ramesh, Chaturvedi Manish, Malker B. (2002) Sexuality and sexual behavior in male adolescent school students BJH organization Journal. 4404.

[32] Tan M. (1996): Looking for the missing Filipino Bisexual Male. In P. Angleton (ed.) Bisexualities and AIDS: International perspectives, London: Taylor and Francis.

[33] Tanner, J. M. (1971Sequence, Tempo NDS individual variation in the growth and development of boys and girls aged twelve to sixteen. Daedalus 100:907,.

[34] Tracee Cornforth (2006): “About Common Health's Disease and Condition” HIV Institute (See http://hivinsite.ucsf.edu/hiv?page=basics-00-05) A Comprehensive, up-to-date information on HIV/AIDS treatment, prevention, and policy from the University of California San Francisco.

[35] Warwick I. \& Angleton, P. (1990). 'Adolescents, young people and AIDS research'. In P. Aggleton, P. Davis \& Hart (eds.) AIDS: individual, cultural and policy dimensions. Basingtoke, England: Falmer Press.

[36] Warwick I. et al. (1998) Household and Community Responses to AIDS in Developing Countries, Critical Public Health. 
[37] Weiss, E., Whelan, D., Gupta, G. R. (1996). Vulnerability and opportunity: Adolescents and HIV/AIDS in the Developing World. Washington DC: International Center for Research on Women.

[38] Wikipedia (2006) ( http://en.wikipedia.org/wiki/Sex education).

[39] World Health Organization (2003). Maternal and child and Family Planning for Health. Agenda Item 18.2 at $46^{\text {th }}$ World Health Assembly May 12. Geneva. Author.

[40] World Health Organization (1995). Women and AIDS: an agenda for action. Geneva. Author.

[41] World Health Organization (2009). Coming of Age: from facts to action for adolescent sexual and reproductive health. Geneva. Author.

[42] Zelaya E., Marin F. M., Garcia J., Berglund S., Liljestrand, J. \& Persson L. A. (1997). Gender and social differences in Adolescent Sexuality and Reproduction in Nicaragua. Journal of Adolescent Health, 21:39-46. 